Article

\title{
Novel Phototransformable Fluorescent Protein SAASoti with Unique Photochemical Properties
}

\author{
Ilya D. Solovyev ${ }^{1,2}$, Alexandra V. Gavshina ${ }^{2}$ and Alexander P. Savitsky ${ }^{1,2, *}$ \\ 1 Department of Chemistry, M.V. Lomonosov Moscow State University, Leninskie Gory 1/3, \\ Moscow 119991, Russia \\ 2 A.N. Bach Institute of Biochemistry, Research Center of Biotechnology of the Russian Academy of Sciences, \\ Leninsky Ave. 33, bld. 2, Moscow 119071, Russia \\ * Correspondence: apsavitsky@inbi.ras.ru
}

Received: 14 June 2019; Accepted: 8 July 2019; Published: 11 July 2019

check for updates

\begin{abstract}
SAASoti is a unique fluorescent protein (FP) that combines properties of green-to-red photoconversion and reversible photoswitching (in its green state), without any amino acid substitutions in the wild type gene. In the present work, we investigated its ability to photoswitch between fluorescent red ('on') and dark ('off') states. Surprisingly, generated by $400 \mathrm{~nm}$ exposure, the red form of SAASoti (R1) does not exhibit any reversible photoswitching behavior under $550 \mathrm{~nm}$ illumination, while a combination of prior $470 \mathrm{~nm}$ and subsequent $400 \mathrm{~nm}$ irradiation led to the appearance of another- $\mathrm{R} 2$ - form that can be partially photoswitched $(550 \mathrm{~nm})$ to the dark state, with a very fast recovery time. The phenomenon might be explained by chemical modification in the chromophore microenvironment during prior $470 \mathrm{~nm}$ exposure, and the resulting R2 SAASoti differs chemically from the R1 form. The suggestion is supported by the mass spectrometry analysis of the tryptic peptides before and after $470 \mathrm{~nm}$ light exposure, that revealed Met164 oxidation, as proceeds in another dual phototransformable FP, IrisFP.
\end{abstract}

Keywords: fluorescent proteins; photoconversions of fluorescent proteins; reversible photoswitching

\section{Introduction}

Phototransformable fluorescent proteins from Anthozoa organisms are successfully used in fluorescent microscopy of living systems [1-4]. Several types of phototransformation can be distinguished: Photoactivation (PA) - the process of irreversible light-induced transformation from a non-fluorescent to a fluorescent form, (paGFP [5], paRFP [6], PAmCherry [7], PAmKate, etc.); green-to-red photoconversion (PC)-irreversible conversion between two fluorescent states with distinct emission colors, as the process involves the extension of the chromophore from a two-ring GFP-like form to a three-ring one, (EosFP [8], Kaede [9], Maple [10], dendFP [11], PSmOrange [12]); 'on'/'off'-switching-reversible photoswitching between a fluorescent ('on') and a non-fluorescent ('off') states, (Dronpa [13], mTFP0.7 [14], rsEGFP [15], Dreiklang [16,17], KFP [18]). While PA and PC are irreversible photochemical processes, the off/on-switching can be repeated several times with the same sample. There are some genetically engineered fluorescent proteins (FPs), which unite PA and PC properties-IrisFP [19], NijiFP [20], and pcDronpa [21]. Certain photophysical and photochemical properties of fluorescent dyes and FPs gave rise to the appearance of different super-resolution localization methods; e.g., they are the basis of Photo-Activated Localization Microscopy (PALM) methods, and observation of stochastic FP blinking-Super-resolution Optical Fluctuation Imaging (SOFI) methods.

SAASoti was originally discovered in the coral Stylocoeniella armata as an irreversibly green-to-red photoconvertible FP [22]. Green-to-red PC occurs under $400 \mathrm{~nm}$ illumination and is accompanied by a 
peptide bond break, as it proceeds in Kaede-like proteins [11]. A 3D tetrameric model of SAASoti was constructed based on the known Kaede structure (PDB ID: 2GW3) [23]. While the wild type SAASoti exists as a tetramer tending towards aggregation, a V127T point mutation at its hydrophobic interface resulted in the monomeric variant of SAASoti [23]. From here on, we will describe this monomeric form-V127T SAASoti. Recently the green form of SAASoti was found to be reversibly switched 'off' by irradiating the sample at $470 \mathrm{~nm}$ without its PC to the red form [24]. $10 \mathrm{~min}$ of $470 \mathrm{~nm}$ exposure led to an increase in absorption at $395 \mathrm{~nm}$ (chromophore protonated form) and a decrease at $509 \mathrm{~nm}$ (chromophore anionic form). The phenomenon is most likely caused by cis-trans isomerization of the chromophore associated with the change of its protonation state, as it was demonstrated for several reversibly photoswitchable FPs [25].

Interestingly, the F173S point mutation in the case of the photoconvertible FP EosFP led to the appearance of its photoswitching phenomenon (+F191L resulting in IrisFP (Figure 1, blue)) [19], whereas SAASoti is already photoswitchable with phenylalanine occupying the corresponding position-178 (Figure 1). In the case of Dendra2, M159A or F173S mutations caused the same effect. The latter variant had more effective photoswitching to the 'off'-state and was named NijiFP [20].

\begin{tabular}{|c|c|}
\hline Protein & Sequence Alignment \\
\hline & 30 \\
\hline SAASoti & -----MALSKQY IPDDMELI FHMDGCVNGHYFTIVATGKAKPYEGKQNLKATVTKGAPLP \\
\hline Dendra2 & ----MNTPGINLIKEDMRVKVHMEGNVNGHAFVIEGEGKGKPYEGTQTANLTVKEGAPLP \\
\hline Dronpa & --------MSVIKPDMKIKLRMEGAVNGHPFAIEGVGLGKPFEGKQSMDLKVKEGGPLP \\
\hline mMaple & MVSKGEETIMSVIKPDMKIKLRMEGNVNGHAFVIEGEGSGKPFEGIQTIDLEVKEGAPLP \\
\hline Kaede & ------- MSLIKPEMKIKLLMEGNVNGHQFVIEGDGKGHPFEGKQSMDLVVKEGAPLP \\
\hline IrisFP & --------MSAIKPDMKINLRMEGNVNGHHFVIDGDGTGKPFEGKQSMDLEVKEGGPLP \\
\hline \multirow[t]{2}{*}{ EOSFP } & ---------MSAIKPDMKINLRMEGNVNGHHFVIDGDGTGKPFEGKQSMDLEVKEGGPLP \\
\hline & $56 \quad 60$ \\
\hline SAASoti & FSTDILSTVMHYGNRCIVHYPPGILDYFKQSFPEGYSWERTFAFEDGGFCTASADIKLKD \\
\hline Dendra2 & FSYDILTTAVHYGNRVFTKYPEDI PDYFKQSFPEGYSWERTMTFEDKGICTIRSDISLEG \\
\hline Dronpa & FAYDILTTVFCYGNRVFAKYPENIVDYFKQSFPEGYSWERSMNYEDGGICNATNDITLDG \\
\hline maple & FAYDILTTAFHYGNRVFTKYPEDI PDYFKQSFPEGYSWERSMTYEDGGICIATNDITMEE \\
\hline Kaede & FAYDILTTAFHYGNRVFAKYPDHI PDYFKQSFPKGF SWERSLMFEDGGVCIATNDITLKG \\
\hline IrisFP & FAFDILTTAFHYGNRVFAEYPDHIQDYFKQSFPKGYSWERSLTFEDGGICIARNDITMEG \\
\hline \multirow[t]{2}{*}{ EOSFP } & FAFDILTTAFHYGNRVFAEYPDHIQDYFKQSFPKGYSWERSLTFEDGGICIARNDITMEG \\
\hline & 116120 \\
\hline $\mathrm{SAA}$ & NCFI HT SMFHGVNF PADGPVMQRKTIQWEKSIEKMTVSDGIVKGDITMFLLLEGGGKYRC \\
\hline Dendra2 & DCFFQNVRFKGTNFPPNGPVMQKKTLKWEPSTEKLHVRDGLLVGNINMALLLEGGGHYLC \\
\hline Dronpa & DCYIYEIRFDGVNFPANGPVMQKRTVKWEPSTEKLYVRDGVLKGDVNMALSLEGGGHYRC \\
\hline mMaple & DSFINKIHFKGTNFPPNGPVMQKRTVGWEVSTEKMYVRDGVLKGDVKMKLLLKGGSHYRC \\
\hline Kaede & DTFFNKVRFDGVNFPPNGPVMQKKTLKWEASTEKMYLRDGVLTGDITMALLLKGDVHYRC \\
\hline IrisFP & DTFYNKVRFHGVNF PANGPVMQKKTLKWEPSTEKMYVRDGVLTGDITMALLLEGNAHYRC \\
\hline \multirow[t]{2}{*}{ EOSFP } & DTFYNKVRFHGVNFPANGPVMQKKTLKWEPSTEKMYVRDGVLTGDITMALLLEGNAHYRC \\
\hline & 176180 \\
\hline SAASoti & QFHTSYKAK-KVVEMPQSHYVEHSIERTNDD--GTQFELNEHAVARLNE-------- \\
\hline Dendra2 & DFKTTYKAK-KVVQLPDAHFVDHRIE ILGNDSDYNKVKLYEHAVARYSPLPSQVW-- \\
\hline Dronpa & DFKTTYKAK-KVVQLPDYHFVDHHIE IKSHDKDYSNVNLHEHAEAHSEL-PRQAK--- \\
\hline mMaple & DFRTTYKVKQKAVKLPDYHFVDHRIE ILSHDKDYNKVKLYEHAVARNSTDSMDELYK \\
\hline Kaede & DFRTTYKSRQEGVKLPGYHFVDHCIS ILRHDKDYNEVKLYEHAVAHSGLPDNVK--- \\
\hline IrisFP & DSRTTYKAKEKGVKLPGYHLVDHCIE ILSHDKDYNKVKLYEHAVAHSGLPDNARR-- \\
\hline EOSFP & DFRTTYKAKEKGVKLPGYHFVDHCIE ILSHDKDYNKVKLYEHAVAHSGLPDNARR-- \\
\hline
\end{tabular}

Figure 1. SAASoti sequence alignment with other phototransformable fluorescent proteins (SAASoti numbering). Yellow-Dronpa to pcDronpa mutation points; grey-critical points for photoswitching appearance in case of EosFP; Dendra2; green-'off'-state stabilization points.

Another way to obtain FPs with dual phototransformation nature is to force already photoswitchable proteins to become also photoconvertible, as it was done with Dronpa-a classic photoswitchable FP—that became pcDronpa after C62H/N94S/N102I/E218G/V60A (Figure 1, yellow) mutations [21], where $\mathrm{C} 62 \mathrm{H}$ is the key point mutation, as all Kaede-like pcFPs carry conserved the 
H-Y-G chromophore folding triad. In other words, SAASoti is the first wild type FP described to date possessing both green-to-red PC and reversible photoswitching.

\section{Results}

\subsection{Photoswitching of the Green Form of SAASoti}

The 'off'-switching process can be reversed either by illumination at $400 \mathrm{~nm}$ or during thermal relaxation. Previously, we investigated thermal relaxation and calculated corresponding constants $\left(\tau_{1 / 2}\right.$ $=30 \mathrm{~min}$ at $25^{\circ} \mathrm{C}$ ) as SAASoti can be irreversibly converted into the red fluorescent form by $400 \mathrm{~nm}$ illumination at $\mathrm{pH} 7.5$ [24]. Figure 2 shows that 'off'-switching with subsequent $400 \mathrm{~nm}$ illumination of the probe can be repeated with the same sample several times without PC to the red form at $\mathrm{pH} 9.2$ (pH-dependency of SAASoti PC was done previously [23]). Green fluorescence photoswitching to the dark state (Figure 2A) at $470 \mathrm{~nm}\left(160 \mathrm{~mW} / \mathrm{cm}^{2}\right)$ can be described by a bi-exponential model (Figure S1A). Typically, different types of monomolecular parallel, sequential reactions and their combinations can be described as the sum of the exponential functions (Equation (1)). In the case of the green form photoswitching, the first exponent is the same through all the cycles and is equal to $\mathrm{k}_{1}=7.4 \pm 0.5$ $\times 10^{-3} \mathrm{~s}^{-1}$. The second exponent at the first bleaching cycle has an inverse pre-exponential value that can mean an increase in the fluorescence at the first step with $\mathrm{k}_{2}=1.4 \pm 0.2 \times 10^{-2} \mathrm{~s}^{-1}$, and indicates on photochemical transformations. Subsequent 'off'-switchings have two exponents with the same character- $\mathrm{k}_{1}=7.9 \pm 0.5 \times 10^{-3} \mathrm{~s}^{-1}$ and $\mathrm{k}_{2}=2.6 \pm 0.2 \times 10^{-2} \mathrm{~s}^{-1}$. 'On'-switching agrees with a mono-exponential fluorescence growth (Figure S1B) with $\mathrm{k}_{\text {growth }}=0.44 \pm 0.02 \mathrm{~s}^{-1}$ at $5.7 \mathrm{~mW} / \mathrm{cm}^{2}$ of $400 \mathrm{~nm}$ irradiation power (Figure 2A).

$$
\mathrm{I}(\mathrm{t})=\mathrm{C}+\sum_{\mathrm{i}=1}^{\mathrm{n}} \mathrm{A}_{\mathrm{i}} \times \exp \left(-\mathrm{k}_{\mathrm{i}} \mathrm{t}\right)
$$
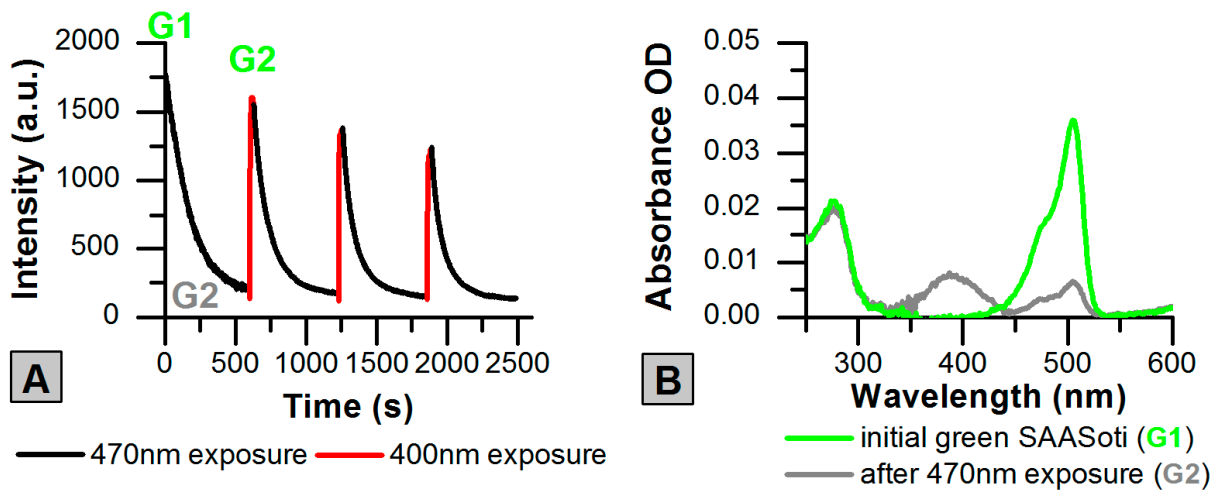

Figure 2. Reversible photoswitching of the green SAASoti $(0.5 \mu \mathrm{M}) .470 \mathrm{~nm}$ illumination $160 \mathrm{~mW} / \mathrm{cm}^{2}$ (10 $\mathrm{min}$ ) and $400 \mathrm{~nm} 5.7 \mathrm{~mW} / \mathrm{cm}^{2}(10 \mathrm{~s}), \mathrm{pH} 9.2,200 \mathrm{mM} \mathrm{NaHCO}_{3}$. (A) Fluorescence intensity at $520 \mathrm{~nm}$ time dependencies; (B) Absorbance spectra of 'on' (green) and 'off' (grey) fluorescent states of SAASoti after first switching cycle.

In other words, when going from the first 'off'-switching cycle to the subsequent ones, the difference in the fluorescence decrease course can be noted. The decrease in the absolute fluorescence intensity between the cycles (Figure 2A) might be caused by the photodestruction of the sample both by $470 \mathrm{~nm}$ (during 'off'-switching) and by illumination at $400 \mathrm{~nm}$ (during 'on'-switching) or because of different extinction coefficients of photochemically transformed SAASoti. Green SAASoti forms before and relaxed after $470 \mathrm{~nm}$ exposure are marked G1 and G2, respectively. 


\subsection{Green-to-Red Photoconversion of SAASoti}

For different photoconvertible FPs, green-to-red PC was shown to proceed incompletely [20]. As it was demonstrated earlier [23], formation of the red form in the case of SAASoti is accomplished by its subsequent photobleaching under $400 \mathrm{~nm}$. Increasing the $400 \mathrm{~nm}$ exposure time in the case of SAASoti leads to the photodestruction of both forms [22]. In other words, some amount of the green form is always present. Interestingly, that combining of prior photobleaching of G1 SAASoti at $470 \mathrm{~nm}$ over $10 \mathrm{~min}$ (generation of G2 form) with subsequent illumination at $400 \mathrm{~nm}$ resulted in accelerated photoconversion (Figure 3A).
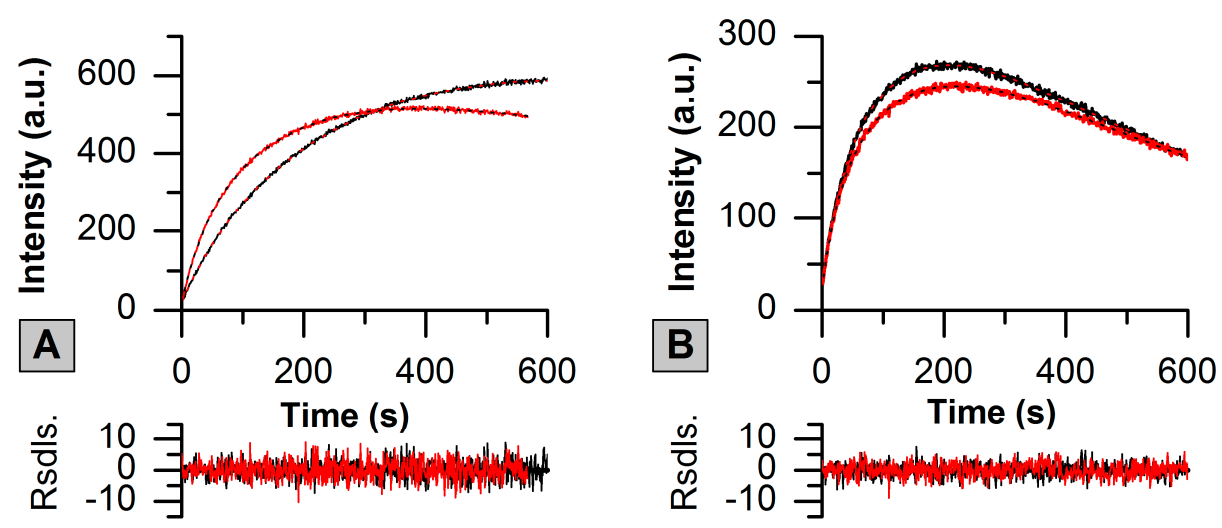

Figure 3. Kinetics of green-to red photoconversion of SAASoti (lines) with three-exponential fits (dots) and the fits' residuals at the bottom. Time dependencies of fluorescence intensity at $590 \mathrm{~nm}$ under 400 nm illumination (black, R1 formation) and with prior $470 \mathrm{~nm}$ light exposure (10 min) of the sample (red, R2 formation). (A) Freshly prepared sample; (B) ‘Old’ SAASoti sample. TBS buffer, pH 7.4.

The idea was to shift the equilibrium between the neutral and anionic states of the chromophore and make it pre-adopted for the PC, as only the neutral chromophore in Kaede-like proteins can be photoconverted to the red form under exposure to ultraviolet light [11]. Dendra2 is an interesting FP that can be photoconverted either by $400 \mathrm{~nm}$ illumination or $488 \mathrm{~nm}$ light (with much less efficiency) [11], making primed conversion possible in this case [26]. As the G2 form instantly returns from the 'off' state during $400 \mathrm{~nm}$ illumination, while green-to-red photoconversion occurs within several minutes, we suggest that some chemical modification of the amino acid residues in the vicinity of the chromophore might take place. In other words, these two forms of SAASoti-G1 and pre-irradiated at $470 \mathrm{~nm}$, G2-are supposed to differ chemically. SAASoti converted by the 'original' technique during exposing the sample to $400 \mathrm{~nm}$ light we will mark R1, and with prior $470 \mathrm{~nm}$ irradiation of the green form-R2. The process is described by a three-exponential function, where $k_{1}$ and $k_{2}$ are responsible for the red form generation and $k_{3}$-for its irreversible photodestruction (Table 1). There is almost no difference in the initial rate value in the red SAASoti formation (Figure 3B) when an old SAASoti sample (storage at $4{ }^{\circ} \mathrm{C}$ for about 6 months without any reductive agent) and pre-irradiated samples were studied. The data is in a good agreement with the chemical modification suggestion.

Table 1. Kinetic parameters in the reaction of green-to-red photoconversion (PC) of SAASoti ( \pm S.E.).

\begin{tabular}{ccccccc}
\hline Conversion & $\begin{array}{c}\mathbf{k}_{\mathbf{1}} \times \mathbf{1 0}^{\mathbf{3}} \\
\left(\mathbf{s}^{\mathbf{- 1}} \mathbf{)}\right.\end{array}$ & $\begin{array}{c}\mathbf{k}_{\mathbf{2}} \times \mathbf{1 0}^{\mathbf{4}} \\
\mathbf{( s}^{\mathbf{- 1}} \mathbf{)}\end{array}$ & $\begin{array}{c}\mathbf{k}_{\mathbf{3}} \times \mathbf{1 0}^{\mathbf{4}} \\
\left(\mathbf{s}^{\mathbf{- 1}} \mathbf{)}\right.\end{array}$ & $\mathbf{A}_{\mathbf{1}}$ (a.u.) & $\mathbf{A}_{\mathbf{2}}$ (a.u.) & $\mathbf{A}_{\mathbf{3}}$ (a.u.) \\
\hline G1 & $13 \pm 1$ & $24 \pm 3$ & $8 \pm 1$ & $-110 \pm 20$ & $-1280 \pm 240$ & $1380 \pm 260$ \\
G2 & $28 \pm 2$ & $59 \pm 3$ & $6 \pm 1$ & $-150 \pm 10$ & $-540 \pm 10$ & $680 \pm 20$ \\
'old' G1 & $36 \pm 2$ & $68 \pm 3$ & $23 \pm 1$ & $-88 \pm 5$ & $-490 \pm 20$ & $570 \pm 30$ \\
'old' G2 & $42 \pm 2$ & $69 \pm 2$ & $19 \pm 5$ & $-81 \pm 4$ & $-381 \pm 12$ & $456 \pm 16$ \\
\hline
\end{tabular}




\subsection{Photoswitching of the Red SAASoti Form}

We also investigated if the red form of SAASoti-R1 and R2-could be photoswitched from their fluorescent 'on' to the 'off'-states and whether this process was reversible. Firstly, we recorded kinetics of the red fluorescence decrease of R1 under $550 \mathrm{~nm}$ illumination $\left(300 \mathrm{~mW} / \mathrm{cm}^{2}\right)$ during $60 \mathrm{~min}$ (by contrast, G1 can be completely 'off'-switched within $10 \mathrm{~min}$ [24]). The process is irreversible as no thermal relaxation or 'off'-to-'on' light-induced photoswitching were observed. The absorbance spectra before and after $550 \mathrm{~nm}$ exposure also did not reveal the presence of the chromophore protonated form (as it was observed in the case of rIrisFP, [19]). The data is not presented. Fluorescence decay during $550 \mathrm{~nm}$ exposure in the case of R1 is most likely caused by the protein's photodestruction (Figure S2A, black line).

On the contrary, when irradiating R2 SAASoti with $550 \mathrm{~nm}$ light we observed some 'on'-'off' photoswitching of this form. It is important to note, that $550 \mathrm{~nm}$ exposure time should not exceed 50-60 s for R2 SAASoti as a second (photodestruction) component dominates in this case. 'Off'-switched R2 form can relax within $10 \mathrm{~min}$ to its fluorescent 'on'-state (G1 relaxes during more than $1 \mathrm{~h}$ ). Moreover, this 'on'-'off' switching can be repeated several times (Figure 4A). It should be noted, that the fluorescence decrease is no more than $20 \%$ of the initial intensity value, while in the case of G1 fluorescence can be completely switched 'off'. Interestingly, when investigating an 'old' SAASoti sample (storage at $4{ }^{\circ} \mathrm{C}$ for about 6 months without any reductive agent) under $550 \mathrm{~nm}$ irradiation for $50 \mathrm{~s}$ and subsequent $10 \mathrm{~min}$ thermal relaxation we also observed some photoswitching (Figure 4B); no more than $10 \%$ of initial intensity for R1 in the case of the 'old' sample.
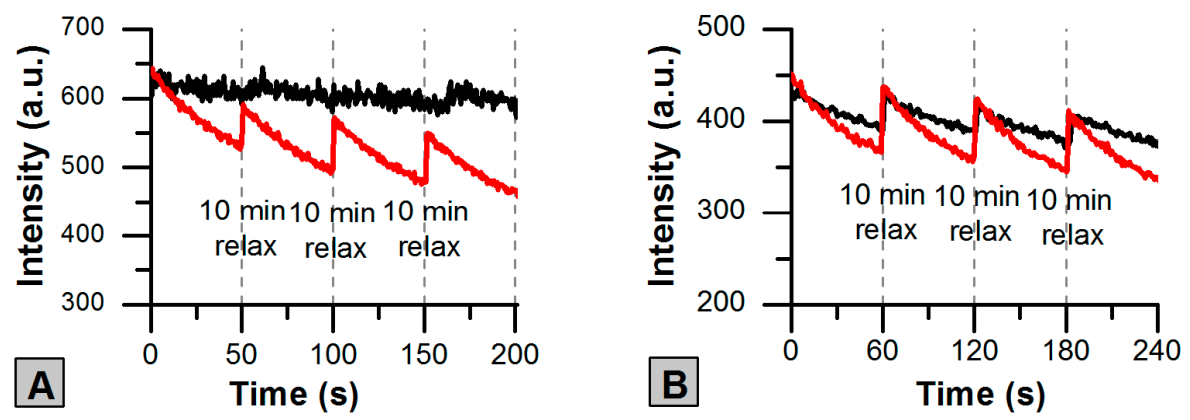

Figure 4. Photoswitching cycles of R1 (black) and R2 (red) SAASoti forms at $550 \mathrm{~nm}\left(300 \mathrm{~mW} / \mathrm{cm}^{2}\right)$ irradiation (50 s) with 10 min relaxations. Time dependencies of the red fluorescence intensities at 590 nm. TBS buffer, pH 7.4. (A) Freshly prepared sample; (B) old SAASoti sample.

Absorbance spectra of the R2 form before and after $550 \mathrm{~nm}$ illumination during $50 \mathrm{~s}$ revealed the decrease of $573 \mathrm{~nm}$ maxima and a minor peak broadening in the range of 400-500 nm (Figure 5A). Spectral changes could be presented more clearly by the subtraction of the initial R2 absorbance spectrum from the spectrum of the exposed to $550 \mathrm{~nm}$ light protein (Figure 5B). Increasing absorbance at $400-500 \mathrm{~nm}$ is probably caused by the protonation of the red form, but because of the small extinction coefficient of the protonated form and superposition with the green anionic spectra, the effect is barely visible.

The red fluorescence decrease is described by a bi-exponential function (Equation (1)), where the first component is responsible for a reversible photoswitch and the second one-for the photodestruction (Figure S2, Table 2).

Taking into account all data on SAASoti phototransformations and experiments on 'old' samples received so far, we can suggest that there exists a difference between chromophore environments in R1 and R2 SAASoti forms. Preliminary exposure to $470 \mathrm{~nm}$ might cause chemical modification that promotes reversible photoswitching (to some extent) of the red form of SAASoti. The phenomenon of the amino acid residue's chemical modification during blue light exposure was shown previously 
when studying another dual phototransformable protein IrisFP [27]. The authors demonstrated Met159 oxidation. In the case of SAASoti, methionine occupies the same position: 164 (Figure 1). MALDI-TOF/TOF was used to identify the difference between G1 and G2 forms that might occur after $470 \mathrm{~nm}$ exposure and might lead to the reversible photoswitching of the R2 form. As can be seen from Figure S3, $10 \mathrm{~min}$ exposure to $470 \mathrm{~nm}$ light leads to the appearance of a 1466.7 Da peptide from a 1450.7 Da one, but the latter is still present in the irradiated sample, indicating an incomplete photo-oxidation reaction (see Tables S1 and S2). The 16 Da mass shift is caused by the methionine 164 oxidation, as it follows from the fragmentation spectrum of 1466.7 Da peptide (Figure S4). Thus, we succeeded to identify one of the possible photochemical modifications in the close vicinity of the chromophore. On this basis, we suggest the main scheme (Scheme 1) of possible transformations between different forms of SAASoti.

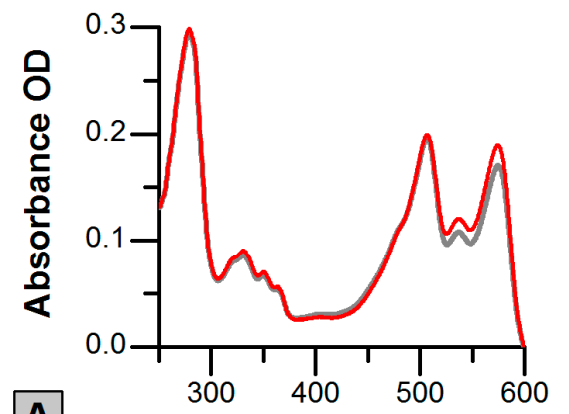

A Wavelength (nm)

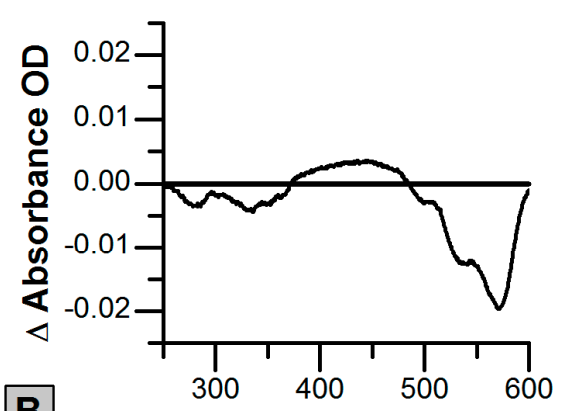

Wavelength $(\mathrm{nm})$

init red form $\longrightarrow 550 \mathrm{~nm}$ exposured

Figure 5. Absorbance spectra of R2 SAASoti (A) before (red line) and after $50 \mathrm{~s} 550 \mathrm{~nm}$ exposure (grey line). (B) The subtraction of initial R2 absorbance spectrum from the $550 \mathrm{~nm}$ (50 s) exposed protein spectrum.

Table 2. Kinetic parameters in the reaction of 'on'-'off'-switching of red SAASoti forms ( \pm S.E.).

\begin{tabular}{|c|c|c|c|c|}
\hline Switching & $\mathrm{k}_{1} \times 10^{2}\left(\mathrm{~s}^{-1}\right)$ & $k_{2} \times 10^{4}\left(s^{-1}\right)$ & $A_{1}$ (a.u.) & $A_{2}$ (a.u.) \\
\hline R1 & $5 \pm 2$ & $12 \pm 2$ & $6 \pm 1$ & $352 \pm 2$ \\
\hline $\mathrm{R} 2$ & $24 \pm 1$ & $6 \pm 1$ & $140 \pm 6$ & $470 \pm 7$ \\
\hline 'old' R1 & $13 \pm 1$ & $3 \pm 1$ & $52 \pm 1$ & $326 \pm 1$ \\
\hline 'old' R2 & $17 \pm 1$ & $3 \pm 1$ & $99 \pm 1$ & $277 \pm 1$ \\
\hline
\end{tabular}

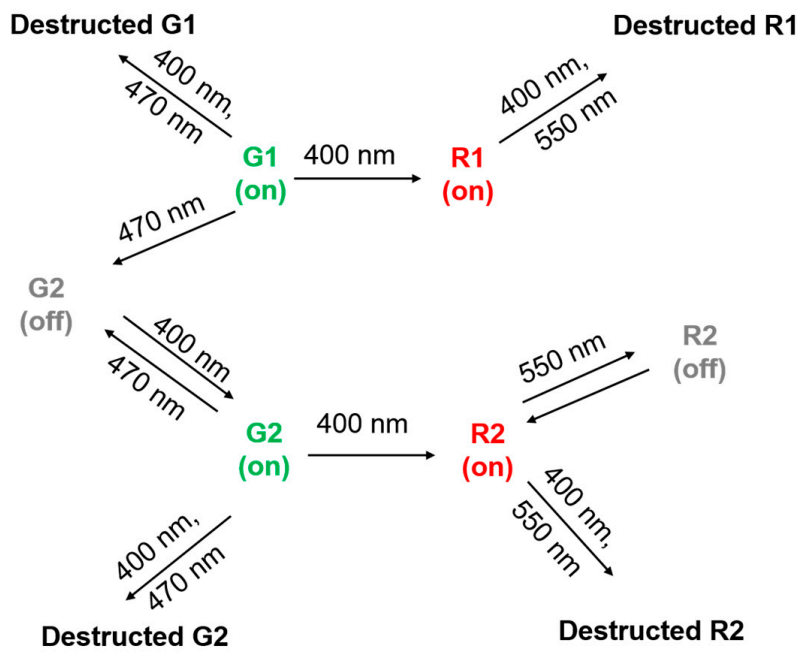

Scheme 1. Phototransformations between different SAASoti forms. 


\section{Discussion}

Photoconvertible and photoswitchable (in their green form) FPs pcDronpa and pcDronpa2 do not possess any red form switching [21]. By comparing this fact with the data received on the red form of IrisFP [19], that can be completely 'off'-switched, the authors [21] suppose that the phenomenon can be explained by the reduced rotational freedom of the chromophore in the case of pcDronpa2. The switching efficiency in the case of NijiFP is equal to $~ 95 \%$ (green form) and $~ 80 \%$ (red form) [20].

Unlike G1, R1 SAASoti does not exhibit any significant reversible photoswitching. Only generated from preliminarily 'off' switched green form-R2 shows limited photoswitching under $550 \mathrm{~nm}$ exposure for $50 \mathrm{~s}$, and increasing the exposure time leads to the irreversible photodestruction. There are at least two suggestions for explaining the phenomenon. R2 SAASoti in its 'off'-state might have a lower pKa value than that of the green dark state. The pKa shift may appear by position changing of the nearest amino acid residues in comparison with the green form, or photochemical modification of an amino acid during photoconversion or photoswitching. Dark states are stabilized by the tetrad Arg66-Ser142-His194-Glu212 (Figure 1, green) in most switchable and multi-photochromic proteins $[19,20]$.

In the case of IrisFP, the red form crystal structure is resolved as a cis- and trans-form mixture [19]. We suppose that the red state of SAASoti undergoes partial twisting with a fast recovery time. In spite of the fact that all GFP-like proteins share common structure and key amino acid residues, the unique nature of the chromophore microenvironment has a direct impact on the FP's properties, being the cause of such a distinct diversity in the GFP-family and even in the subfamilies (e.g., Kaede-like proteins). SAASoti is an interesting example of when a combination of properties do not exactly fit in the proposed conceptions of FP phototransformations, and further investigations on this protein may shed light on its unique phototransformative nature.

\section{Materials and Methods}

\subsection{Protein Expression and Purification}

V127T SAASoti was overexpressed in E. coli BL21 (DE3) as described previously [23]. Protein purity was analyzed by gel-electrophoresis.

\subsection{Absorbance and Fluorescence Measurements}

Absorption spectra were measured in the range $250-700 \mathrm{~nm}$ using a Shimadzu UV-1650 spectrophotometer (Kyoto, Japan) and a $3 \mathrm{~mm}$ quartz micro-cuvette (Hellma, Mülheim, Germany). Samples were dissolved in $20 \mathrm{mM}$ Tris- $\mathrm{HCl}, 150 \mathrm{mM} \mathrm{NaCl}, \mathrm{pH} 7.5$ buffer if not stated otherwise. A Cary Eclipse spectrofluorimeter (Varian, Mulgrave, Australia) with a $3 \mathrm{~mm}$ quartz microcuvette was used for measurements for excitation in the range $250-600 \mathrm{~nm}$ and for fluorescence in the range 450-700 nm. Excitation and emission slits were set to $5 \mathrm{~nm}$. Fluorescence spectra, photoconversion and photobleaching kinetics of the red form of the protein were obtained on a fiber optic SpectrClaster (Moscow, Russia) spectrometer in the spectral range 400-900 nm, as described previously [24] and on a Cary Eclipse fluorescence spectrometer (Varian, Mulgrave, Australia) in the spectral range 450-750 nm. The kinetic experiments were repeated as least three times. Kinetic fits and spectra were performed using Origin 8.5 software.

\subsection{Mass Spectrometry}

The sample of G2 SAASoti for mass-spectrometry was obtained in cuvette at $470 \mathrm{~nm}$ (160 $\mathrm{mW} / \mathrm{cm}^{2}$ ) over $10 \mathrm{~min}$. The subsequent sample preparation of $\mathrm{G} 1$ and $\mathrm{G} 2$ solutions was performed as it was describer earlier [23]. Mass spectra were obtained using a MALDI-TOF Ultraflextreme BRUKER mass spectrometer (Bruker Daltonics, Bremen, Germany). Mass spectra were analyzed using FlexAnalysis 3.3 software (Bruker Daltonics, Bremen, Germany). Comparison of experimentally determined and calculated masses of tryptic peptides of SAASoti were performed using Mascot 
software (www.matrixscience.com). Searches were performed by taking into account the possible oxidation of methionine and cysteine residues, or glutamate decarboxilation by $470 \mathrm{~nm}$ irradiation and formation of a heterocycle in the fluorophore. In order to verify the presence or absence of modifications we obtained fragmentation spectra for distinct peptides (1466.7 Da). Combined analysis of the MS + MS/MS results was performed with Biotools 3.2 (Bruker Daltonics) software. Combined analysis of the MS + MS/MS results was performed with Biotools 3.2 (Bruker Daltonics) software.

Supplementary Materials: Supplementary materials can be found at http://www.mdpi.com/1422-0067/20/14/ 3399/s1.

Author Contributions: I.D.S. wrote the manuscript, absorbance, fluorescence and photochemical experiments, preparation of the Table 1, Table 2 and Figure 1, Figure 2, Figure 3; A.V.G. wrote the manuscript, protein isolation and purification, photochemical experiments (Figures 4 and 5), analysis of MS and chemical modification data (Supplementary Materials); A.P.S. leadership of the work process, experiment planning, wrote the manuscript. All authors reviewed the manuscript.

Funding: This work was supported by the Russian Science Foundation, project No 19-14-00373.

Acknowledgments: Mass spectrometry measurements were carried out on the equipment of the Shared-Access Equipment Centre "Industrial Biotechnology" of Federal Research Center "Fundamentals of Biotechnology," Russian Academy of Sciences.

Conflicts of Interest: The authors declare no conflicts of interest.

\section{References}

1. Betzig, E.; Patterson, G.H.; Sougrat, R.; Lindwasser, O.W.; Olenych, S.; Bonifacino, J.S.; Davidson, M.W.; Lippincott-Schwartz, J.; Hess, H.F. Imaging Intracellular Fluorescent Proteins at Nanometer Resolution. Science 2006, 313, 1642-1645. [CrossRef] [PubMed]

2. Hess, S.T.; Girirajan, T.P.K.; Mason, M.D. Ultra-High Resolution Imaging by Fluorescence Photoactivation Localization Microscopy. Biophys. J. 2006, 91, 4258-4272. [CrossRef] [PubMed]

3. Zhang, L.; Gurskaya, N.; Merzlyak, E.; Staroverov, D.; Mudrik, N.; Samarkina, O.; Vinokurov, L.; Lukyanov, S.; Lukyanov, K. Method for real-time monitoring of protein degradation at the single cell level. BioTechniques 2007, 42, 446-450. [CrossRef] [PubMed]

4. Fuchs, J.; Böhme, S.; Oswald, F.; Hedde, P.N.; Krause, M.; Wiedenmann, J.; Nienhaus, G.U. A photoactivatable marker protein for pulse-chase imaging with superresolution. Nat. Methods 2010, 7, 627-630. [CrossRef] [PubMed]

5. Patterson, G.H.; Lippincott-Schwartz, J. A Photoactivatable GFP for Selective Photolabeling of Proteins and Cells. Science 2002, 297, 1873-1877. [CrossRef] [PubMed]

6. Subach, F.V.; Patterson, G.H.; Renz, M.; Lippincott-Schwartz, J.; Verkhusha, V.V. Bright Monomeric Photoactivatable Red Fluorescent Protein for Two-Color Super-Resolution sptPALM of Live Cells. J. Am. Chem. Soc. 2010, 132, 6481-6491. [CrossRef] [PubMed]

7. Subach, F.V.; Patterson, G.H.; Manley, S.; Gillette, J.M.; Lippincott-Schwartz, J.; Verkhusha, V.V. Photoactivatable mCherry for high-resolution two-color fluorescence microscopy. Nat. Methods 2009, 6, 153-159. [CrossRef]

8. Wiedenmann, J.; Ivanchenko, S.; Oswald, F.; Schmitt, F.; Röcker, C.; Salih, A.; Spindler, K.-D.; Nienhaus, G.U. EosFP, a fluorescent marker protein with UV-inducible green-to-red fluorescence conversion. Proc. Natl. Acad. Sci. USA 2004, 101, 15905-15910. [CrossRef]

9. Ando, R.; Hama, H.; Yamamoto-Hino, M.; Mizuno, H.; Miyawaki, A. An optical marker based on the UV-induced green-to-red photoconversion of a fluorescent protein. Proc. Natl. Acad. Sci. USA 2002, 99, 12651-12656. [CrossRef]

10. McEvoy, A.L.; Hoi, H.; Bates, M.; Platonova, E.; Cranfill, P.J.; Baird, M.A.; Davidson, M.W.; Ewers, H.; Liphardt, J.; Campbell, R.E. mMaple: A Photoconvertible Fluorescent Protein for Use in Multiple Imaging Modalities. PLoS ONE 2012, 7, e51314. [CrossRef]

11. Gurskaya, N.G.; Verkhusha, V.V.; Shcheglov, A.S.; Staroverov, D.B.; Chepurnykh, T.V.; Fradkov, A.F.; Lukyanov, S.; Lukyanov, K.A. Engineering of a monomeric green-to-red photoactivatable fluorescent protein induced by blue light. Nat. Biotechnol. 2006, 24, 461-465. [CrossRef] [PubMed] 
12. Subach, O.M.; Patterson, G.H.; Ting, L.-M.; Wang, Y.; Condeelis, J.S.; Verkhusha, V.V. A photoswitchable orange-to-far-red fluorescent protein, PSmOrange. Nat. Methods 2011, 8, 771-777. [CrossRef] [PubMed]

13. Dedecker, P.; Hotta, J.-I.; Ando, R.; Miyawaki, A.; Engelborghs, Y.; Hofkens, J. Fast and Reversible Photoswitching of the Fluorescent Protein Dronpa as Evidenced by Fluorescence Correlation Spectroscopy. Biophys. J. 2006, 91, L45-L47. [CrossRef]

14. Ai, H.; Campbell, R. Teal fluorescent proteins: Characterization of a reversibly photoswitchable variant. Proc. SPIE 2008, 6868, 68680D.

15. Grotjohann, T.; Testa, I.; Leutenegger, M.; Bock, H.; Urban, N.T.; Lavoie-Cardinal, F.; Willig, K.I.; Eggeling, C.; Jakobs, S.; Hell, S.W. Diffraction-unlimited all-optical imaging and writing with a photochromic GFP. Nature 2011, 478, 204-208. [CrossRef]

16. Brakemann, T.; Stiel, A.C.; Weber, G.; Andresen, M.; Testa, I.; Grotjohann, T.; Leutenegger, M.; Plessmann, U.; Urlaub, H.; Eggeling, C.; et al. A reversibly photoswitchable GFP-like protein with fluorescence excitation decoupled from switching. Nat. Biotechnol. 2011, 29, 942-947. [CrossRef]

17. Gunewardene, M.S.; Subach, F.V.; Gould, T.J.; Penoncello, G.P.; Gudheti, M.V.; Verkhusha, V.V.; Hess, S.T. Superresolution Imaging of Multiple Fluorescent Proteins with Highly Overlapping Emission Spectra in Living Cells. Biophys. J. 2011, 101, 1522-1528. [CrossRef]

18. Lukyanov, K.A. Natural Animal Coloration Can be Determined by a Nonfluorescent Green Fluorescent Protein Homolog. J. Boil. Chem. 2000, 275, 25879-25882. [CrossRef]

19. Adam, V.; Lelimousin, M.; Boehme, S.; Desfonds, G.; Nienhaus, K.; Field, M.J.; Wiedenmann, J.; McSweeney, S.; Nienhaus, G.U.; Bourgeois, D. Structural characterization of IrisFP, an optical highlighter undergoing multiple photo-induced transformations. Proc. Natl. Acad. Sci. USA 2008, 105, 18343-18348. [CrossRef]

20. Adam, V.; Moeyaert, B.; David, C.C.; Mizuno, H.; Lelimousin, M.; Dedecker, P.; Ando, R.; Miyawaki, A.; Michiels, J.; Engelborghs, Y.; et al. Rational Design of Photoconvertible and Biphotochromic Fluorescent Proteins for Advanced Microscopy Applications. Chem. Boil. 2011, 18, 1241-1251. [CrossRef]

21. Moeyaert, B.; Bich, N.N.; De Zitter, E.; Rocha, S.; Clays, K.; Mizuno, H.; Van Meervelt, L.; Hofkens, J.; Dedecker, P. Green-to-Red Photoconvertible Dronpa Mutant for Multimodal Super-resolution Fluorescence Microscopy. ACS Nano 2014, 8, 1664-1673. [CrossRef] [PubMed]

22. Lapshin, G.; Salih, A.; Kolosov, P.; Golovkina, M.; Zavorotnyi, Y.; Ivashina, T.; Vinokurov, L.; Bagratashvili, V.; Savitsky, A. Fluorescence color diversity of great barrier reef corals. J. Innov. Opt. Heal. Sci. 2015, 8, 1550028. [CrossRef]

23. Solovyev, I.D.; Gavshina, A.V.; Katti, A.S.; Chizhik, A.I.; Vinokurov, L.M.; Lapshin, G.D.; Ivashina, T.V.; Khrenova, M.G.; Kireev, I.I.; Gregor, I.; et al. Monomerization of the photoconvertible fluorescent protein SAASoti by rational mutagenesis of single amino acids. Sci. Rep. 2018, 8, 15542. [CrossRef] [PubMed]

24. Solovyev, I.; Gavshina, A.; Savitsky, A. Reversible photobleaching of photoconvertible SAASoti-FP. J. Biomed. Photon. Eng. 2017, 3. [CrossRef]

25. Voliani, V.; Bizzarri, R.; Nifosì, R.; Abbruzzetti, S.; Grandi, E.; Viappiani, C.; Beltram, F. Cis-Trans Photoisomerization of Fluorescent-Protein Chromophores. J. Phys. Chem. B 2008, 112, 10714-10722. [CrossRef]

26. Klementieva, N.V.; Lukyanov, K.A.; Markina, N.M.; Lukyanov, S.A.; Zagaynova, E.V.; Mishin, A.S. Green-to-red primed conversion of Dendra2 using blue and red lasers. Chem. Commun. 2016, 52, 13144-13146. [CrossRef] [PubMed]

27. Duan, C.; Adam, V.; Byrdin, M.; Ridard, J.; Kieffer-Jaquinod, S.; Morlot, C.; Arcizet, D.; Demachy, I.; Bourgeois, D. Structural Evidence for a Two-Regime Photobleaching Mechanism in a Reversibly Switchable Fluorescent Protein. J. Am. Chem. Soc. 2013, 135, 15841-15850. [CrossRef]

(C) 2019 by the authors. Licensee MDPI, Basel, Switzerland. This article is an open access article distributed under the terms and conditions of the Creative Commons Attribution (CC BY) license (http://creativecommons.org/licenses/by/4.0/). 